\title{
Uro-Scanner Aspects of Bladder Tumours at the Mali Hospital about 17 Cases
}

\author{
Mody Abdoulaye Camara1*, Mohamed Maba Traore1, Hawa Diarra1, Adama Dao², \\ Boubacar Mama Toure1, Mamadou Ndiaye3 ${ }^{3}$, Salia Coulibaly ${ }^{3}$, Kone Abdoulayye ${ }^{4}$, \\ Mariko Mahamane ${ }^{5}$, Cisse Issa ${ }^{5}$, Konate Moussa4, Ilias Guindo ${ }^{6}$, Konate Zakaria ${ }^{1}$, \\ Nouhoum Simpara', Seydou Coulibaly ${ }^{1}$, Néné Koumaré7, Siaka Sidibe ${ }^{4}$
}

\author{
${ }^{1}$ Medical Imaging Department of the Mali Hospital, Bamako, Mali \\ ${ }^{2}$ Medical Imaging Department at the CHU Gabriel Touré, Bamako, Mali \\ ${ }^{3}$ Bamako Infirmary Hospital, Bamako, Mali \\ ${ }^{4}$ Medical Imaging Department of the CHU Point G, Bamako, Mali \\ ${ }^{5}$ Medical Imaging Department of CHME Luxembourg, Bamako, Mali \\ ${ }^{6}$ Medical Imaging Department of the CHU of Kati, Bamako, Mali \\ ${ }^{7}$ Pediatric Unit of Reference Health Center of Commune VI, Bamako, Mali \\ Email: *drmacamara@yahoo.fr
}

How to cite this paper: Camara, M.A., Traore, M.M., Diarra, H., Dao, A., Toure, B.M., Ndiaye, M., Coulibaly, S., Abdoulayye, K., Mahamane, M., Issa, C., Moussa, K., Guindo, I., Zakaria, K., Simpara, N., Coulibaly, S., Koumaré, N. and Sidibe, S. (2021) Uro-Scanner Aspects of Bladder Tumours at the Mali Hospital about 17 Cases. Open Journal of Medical Imaging, 11, 93-103.

https://doi.org/10.4236/ojmi.2021.114009

Received: August 28, 2021

Accepted: October 30, 2021

Published: November 2, 2021

Copyright $\odot 2021$ by author(s) and Scientific Research Publishing Inc. This work is licensed under the Creative Commons Attribution International License (CC BY 4.0).

http://creativecommons.org/licenses/by/4.0/

cc) (i) Open Access

\begin{abstract}
Introduction: Bladder tumours are frequent, have a poor prognosis and are the second most common genitourinary tumour in men. In Mali, recent statistical data on the prevalence of bladder tumours show a progression with $6.71 \%$ in 2006 . The euro scanner is used in the diagnostic workup. The work was initiated in order to specify the role of the scanner in the diagnosis of these tumors. Patients and Methods: Prospective descriptive study was carried out in the medical imaging department of Mali Hospital from February to November 2018. Were included any patient with a bladder tumour on euro scanner. The patients had benefited from a preliminary preparation and a renal biological assessment in order to eliminate renal insufficiency. Our examinations were performed with a Siemens 16-slice scanner. These were axial slices performed without, with iodine injection from the pulmonary base to the pubic bones. Results: We had collected 17 patients out of 541 scans i.e. a frequency of $3.76 \%$. The age range of 21 to 40 years was $58.8 \%$ with an average age of 25 years. The antecedents (ATCD) found were urinary bilharzia (47\%) and smoking (17\%). The clinic was dominated by haematuria. It was associated with a bladder mass (52\%) and dysuria (23.52\%). The CT scan showed a budding appearance, a size greater than $3 \mathrm{~cm}$ (82\%), infiltration of peri-vesical fat (47.05\%), and adenopathy (94\%). Associated lesions were: utero-hydronephrosis (58.82\%) and metastases (bone and liver in $11.76 \%$ of cases each). Conclusion: They are frequent and the history of urinary bilharziasis remains the
\end{abstract}


main risk factor in endemic countries. CT scans are essential in the management of this disease. The diagnosis of certainty remains histology.

\section{Keywords}

Bladder Tumour, Uro-CT, Mali Hospital

\section{Introduction}

A bladder tumour is an excessive multiplication of abnormal cells in its mucosa [1] [2]. They account for 3\% of malignant tumour mortality and affect more men than women, $80 \%$ of them after the age of 55. In Europe, the incidence of bladder tumours varies between 6 and 13 per 100,000 inhabitants [3]. It is the 7 th leading cause of cancer mortality in men and the 9th in women [4]. In West Africa, the highest incidences are recorded in Egypt [4], 2.5\% and Senegal [5]. In Mali, they represent $2.3 \%$ of all cancers. In 2006, it was the third most common cancer in men, the sixth in women and the fifth for both sexes combined [6]. The incidence rate is estimated at 3.6/100,000 inhabitants in men and 2.1/100,000 inhabitants in women with a sex ratio of 1.7 in favour of men [7] [8].

$\mathrm{CT}$ is the reference examination for the assessment of extension, which allows the urologist:

$\checkmark$ assess the impact on the upper urinary tract and/or detect the presence of synchronous urothelial lesions in the upper urinary tract;

$\checkmark$ assess the invasion of neighbouring organs and peri-vesical fat;

$\checkmark$ look for adenopathy and/or metastases (the first metastatic sites being the lymph nodes and the lung).

The diagnosis of peri-vesical or peri-lesional fat infiltration has a sensitivity of $89 \%$ and a specificity of $95 \%$ before resection. In contrast, when CT is performed after transurethral bladder resection (TURB), there is an overestimation of peri-bladder fat infiltration. There is an overestimation of extension due to inflammatory changes in the peri-vesical fat [9] [10]. This examination is particularly important to guide the urologist in his or her. This examination is particularly important to guide the urologist in the surgical removal of the tumour, when this has been decided in a multidisciplinary consultation meeting. CT only detects massive invasion of the prostate or seminal vesicles but allows assessment of possible invasion of digestive structures and the existence of visceral metastases (liver and lung). Invasion of the digestive structures, in particular the sigmoid colon or the small intestines, by a dome tumour is diagnosed by frontal, sagittal or oblique multiplanar reformations [10].

Medical imaging is involved in all stages of patient management. It has a place of choice in the assessment of the extension of the disease, the therapeutic decision and the post-therapeutic follow-up [8] [11], in view of the high frequency of this cancer.

Since the opening of our hospital in 2011, we do not have a urology depart- 
ment for the management of patients with bladder tumours, however, each year we record cases of bladder tumours, some of which are at a late stage. In order to assess the status of the department, we initiated this study to specify the place of urinary CT (euro scanner) in the diagnostic workup of bladder tumours in the medical imaging department of the Mali hospital.

\section{Patients and Method}

This was a prospective descriptive study conducted at the medical imaging department of Mali Hospital over a period of 10 months (February to November 2018). All patients who underwent a euro scanner or abdominal scan and who had a bladder tumour during the study period were included in the study. All patients had undergone psychological preparation and renal biology to rule out underlying renal insufficiency.

The variables studied were: sociodemographic (age, sex, history), clinical (haematuria, pelvic mass, dysuria, acute retention of urine) and Scannographics (characteristics of the lesion, tumour extension, impact on the upper urinary tract and secondary lesions).

Our examinations were carried out with a Siemens Emotion 16-slice scanner with an automatic injector from MEDRAD.

Procedure of the examination:

- All patients had received psychological preparation (reassurance and explanation of the procedure) and physical preparation. Creatinemia was measured to rule out underlying renal failure.

- A history of allergy and diabetes treated with the tablets.

- The examination was performed with a full or semi-replete bladder, in a bare-chested patient, free of any object likely to generate artefacts.

- The protocol was four (4) acquisitions (without injection, arterial, portal and urographic). These were $05 \mathrm{~mm}$ axial slices, from the lung bases to the pubic bone. The millimetre reconstructions were done in the bone and parenchymal windows. We injected iodinated contrast medium (CP) $300-350 \mathrm{mg}$ at a dose of $1-2 \mathrm{ml} / \mathrm{kg}$ and a flow rate of $3-4 \mathrm{ml} / \mathrm{second}$ via the venous route [8] [11].

- The examinations were performed by the specialised manipulators and interpreted by the radiologists.

Analysis and data collection:

- Data collection was done on an individual survey form and radiological reports. Data entry was done with Word 2010 software and analysis with SPSS version 23 .

\section{Results}

At the end of a ten-month study in the medical imaging department of the Mali hospital, we had included 17 patients with bladder tumours out of 451 patients referred for abdominal CT or euro scanner, i.e. a frequency of $3.76 \%$. The age 
group 21 to 40 years was the most represented with $58.8 \%$ with an average age of 25 years and a sex ratio of 1.82 . The most frequently found chronic conditions were: urinary bilharzia (47.05\%) and smoking (17.65\%).

In our series, haematuria was the main reason for the request $(n=16)$ in $94.11 \%$ of cases. It was associated with bladder mass $(52.94 \%)$, dysuria $(23.5 \%)$ and extension work-up (17.65\%) (Table 1).

The CT scan showed tumours: single (82.35\%) and double (17.65\%), located on the anteroinferior surface of the bladder in $35 \%$ of the 6 patients $(n=6)$. The appearance was budding (82.35) and flat (17.65). The size of the lesions was greater than $3 \mathrm{~cm}(82 \%)$. Infiltration of the peri-vesical fat in 08 patients $(47.05 \%)$, adenopathy was found in 16 patients (94.11\%) (Figure 1 ).

Table 1. Distribution of patients by socio-demographic and clinical data.

\begin{tabular}{|c|c|c|c|}
\hline \multicolumn{2}{|c|}{ Characteristics } & Effective $(\mathrm{n}=17)$ & Percentage \\
\hline \multirow{2}{*}{ Age (year) } & Average age & 25 & \\
\hline & $21-40$ & 9 & 52.94 \\
\hline \multirow{2}{*}{ Gender } & Male & 11 & 64.70 \\
\hline & Female & 6 & 35.30 \\
\hline \multirow{5}{*}{ Risk Factors } & Bilharzia & 8 & 47.05 \\
\hline & Smoking/Tabacco & 3 & 17.65 \\
\hline & chronic Cystitis & 2 & 11.76 \\
\hline & Dye & 1 & 5.89 \\
\hline & Absent & 3 & 17.65 \\
\hline \multirow{3}{*}{ Occupation } & Farmer & 5 & 29.41 \\
\hline & Housewife & 4 & 23.54 \\
\hline & Civil servant & 3 & 11.76 \\
\hline \multirow{4}{*}{ The clinic } & Haematuria + dysuria & 4 & 23.5 \\
\hline & Haematuria + bladder mass & 9 & 52.9 \\
\hline & Assessment extension & 3 & 17.65 \\
\hline & Dysuria & 1 & \\
\hline
\end{tabular}

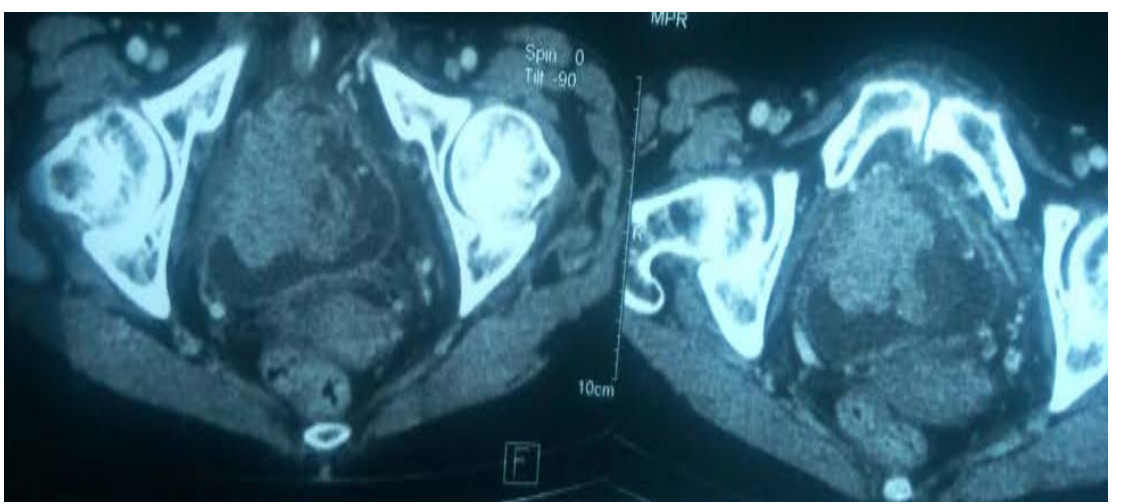

Figure 1. Uro-CT: injected axial sections showing a heterogeneous budding bladder mass of the right anterolateral wall with a sessile implantation base. 
The CT scan revealed utero-hydronephrosis in $58.82 \%$ of patients, $11.76 \%$ of whom had an impact on renal function (Figure 2).

Secondary locations: bone and liver were found in $11.76 \%$ each (Figure 3 ) (Table 2). Only nine (9) patients had provided the results of their histology. The histology found revealed squamous cell carcinoma in $52.94 \%$ of the patients.

\section{Discussion}

\subsection{Socio-Demographic and Clinical}

Over a period of 10 months (February to November 2018), at the Mali hospital, we included 17 cases of bladder tumour out of 451 abdominopelvic scans performed, i.e. a frequency of $3.76 \%$. Our data was higher than that of DIARRA B [12] who found a frequency of $1.5 \%$ over a period of 15 months. This difference can be explained by the sampling: the size, the duration of the study and the

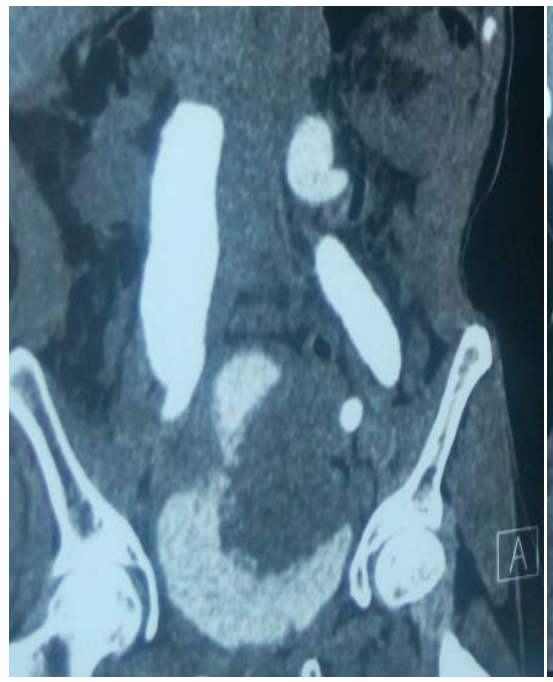

(a)

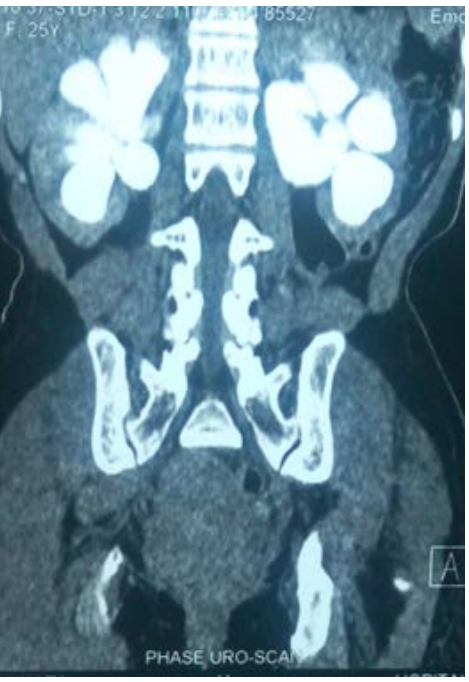

(b)

Figure 2. ( $\mathrm{a}$ and b): Uro-CT: coronal sections in urographic phase showing: tumourous and irregular thickening of the left posterolateral wall and bladder ceiling with bilateral stage 4 hydronephrosis by infiltration of the ureters.

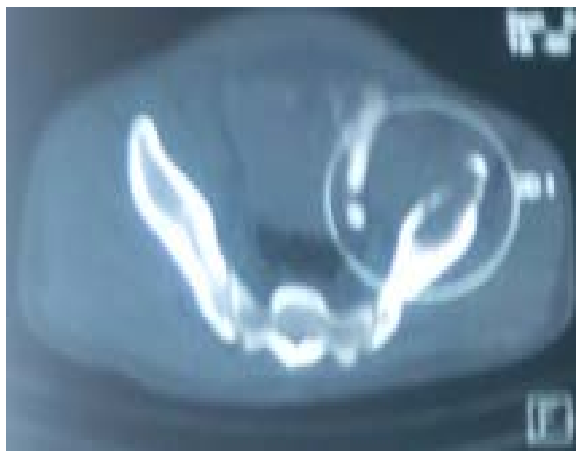

(a)

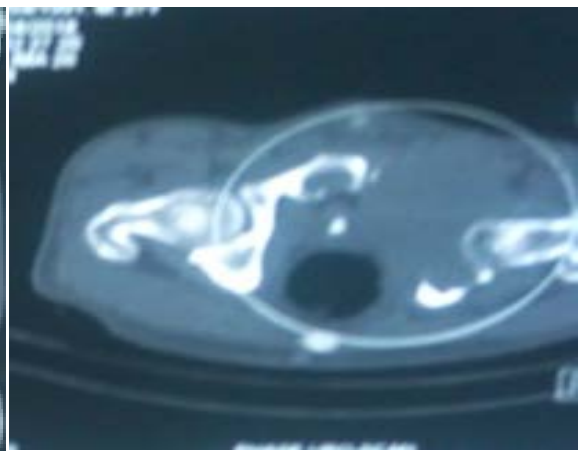

(b)

Figure 3. ( $\mathrm{a}$ and $\mathrm{b}$ ): Pelvic CT: axial slices, in the bone window, showing iliac lyses suggestive of bone metastases. 
Table 2. Distribution of patients according to scan data.

\begin{tabular}{|c|c|c|c|}
\hline \multicolumn{2}{|c|}{ CT Characteristics } & Effective $(\mathrm{n}=17)$ & Percentage \% \\
\hline \multirow{2}{*}{ Tissue density } & Homogeneous & 4 & 23.53 \\
\hline & Heterogeneous + calcifications & 13 & 76.47 \\
\hline \multirow{2}{*}{ Number } & Single & 14 & 82.35 \\
\hline & Multiple & 3 & 17.65 \\
\hline \multirow{2}{*}{ Size } & Greater than $3 \mathrm{~cm}$ & 14 & 82.35 \\
\hline & Less than $3 \mathrm{~cm}$ & 3 & 17.64 \\
\hline \multirow{2}{*}{ Form } & Budding & 14 & 82.35 \\
\hline & Flat & 3 & 17.64 \\
\hline \multirow{4}{*}{ Location } & Antero-lateral & 6 & 35.29 \\
\hline & Posterior & 2 & 11.76 \\
\hline & Ceiling & 2 & 11.76 \\
\hline & Postero-superieor & 7 & 41.18 \\
\hline \multirow{2}{*}{ Iodine enhancement } & Heterogeneous & 13 & 76.47 \\
\hline & Homogeneous & 4 & 23.53 \\
\hline \multirow{3}{*}{ Urinary Retention } & Unilateral & 4 & 23.53 \\
\hline & Bilateral & 6 & 35.29 \\
\hline & Absent & 7 & 41.18 \\
\hline \multirow{3}{*}{$\begin{array}{l}\text { Lymph node } \\
\text { involvement }\end{array}$} & Internal & 3 & 17.65 \\
\hline & Internal and external iliac & 10 & 58.82 \\
\hline & Lombo-aortic & 3 & 17.64 \\
\hline \multirow{3}{*}{$\begin{array}{l}\text { Loco-regional } \\
\text { involvement }\end{array}$} & Peri-bladder flat & 8 & 47.05 \\
\hline & Ureter & 8 & 47.05 \\
\hline & Absent & 1 & \\
\hline \multirow{2}{*}{ Distance involvement } & Bone & 2 & 11.76 \\
\hline & Liver & 2 & 11.76 \\
\hline
\end{tabular}

sampling method. The 21 - 40 age group accounted for $52.9 \%$ and a sex ratio of 1.83. Our figures are lower than those of DIARRA B (59.5\%) [12]. Peyromaure $\mathrm{M}$ et al. [13] found 55\% men. In our series, the average age was 25 years, with extremes of [21 to 60 years]. This age was higher in the studies: Fahmy N [14] who found an average age of 69 years at the time of diagnosis. The young age of our patients can be explained by the youth of the population, but also by the history of Bilharzia and exposure to chemicals (tobacco and dyes) on the one hand, and the absence of a urology department at the hospital in Mali on the other. We did not find any scientific correlation between the sex and age of the patients with regard to the occurrence of the tumour. The main risk factor in our study was urinary bilharzia (47\%) and smoking (17\%). Our results were similar to those of Sangho H [6] and Diarra B [12]. However, they are different from 
those of Elmahfoudi A [15] whose main risk factor was smoking with $45 \%$ of cases. This difference can be explained by environmental and behavioural factors. In our series, farmers were the most concerned (29\%). This figure was similar to that of Tanagra S [16] (29\%). Haematuria was the main reason for uro-CT examination. It was associated with a bladder mass (52\%). Gurou [17] reported $58.14 \%$ of bladder mass associated with haematuria. The presence of a bladder mass associated with haematuria could be explained by the fact that patients consulted at a relatively late stage of the disease.

\subsection{Scannographics Data}

$\mathrm{CT}$ is the reference examination for the exploration of the upper excretory tract. Its sensitivity is $96 \%$ and specificity $99 \%$ for a polypoid lesion greater than or equal to $10 \mathrm{~mm}$ [13]. We report that the patients had already undergone a vesico-renal ultrasound.

1) Tumour characteristics

Tumours of heterogeneous tissue density concerned $71 \%$ of the tumours, like those in the series by Tanagra S [16] and Zerbib M [18], who found heterogeneous tissue density and iodine contrast (76.5\%). These could be explained by the presence of areas of necrosis and calcifications. The calcifications could be in favour of a bilharzia origin. The enhancement is a good argument for differential diagnosis with clots. The tumour contours were irregular in $80 \%$ of cases. This is the most common appearance with 70\% [8] [19]. The irregularity of the contours is a sign of malignancy and infiltration of the muscularis. The lesion was single and larger than $3 \mathrm{~cm}$ (82\%). Single focal sites were found (90\%) of cases suspected of malignancy. According to Roy C et al. [8], there is no preferential site and in the majority of cases, the lesions are multifocal. The tumours were of the budding type (82.4\%) and most often located on the anteroinferior surface in $35 \%$ of cases. Tumour size greater than $3 \mathrm{~cm}$, budding, with heterogeneous contrast are factors of neoplastic presumption and indicate a delay in diagnosis [8] [19] [20].

2) Associated lesions

Upper urinary tract involvement was found in 59\% of patients and bilateral involvement was found in $35 \%$ of cases. A similar study found ureterohydronephrosis [16] [20]. This indicates a degree of infiltration of the ureteral meatus.

Delayed secretion and renal excretion of the contrast medium were found in $20 \%$ of our patients. This rate was lower than that of Diarra B [12] which found $28.37 \%$ of cases. This is a criterion for assessing the functional quality of the kidneys. Suspected adenopathies were found (95\%), predominantly at the internal and external iliac levels (59\%). Infiltration of the peri-bladder fat and the ureters were the most common findings in $47 \%$ of cases. This is described in the literature: Roy C [8] and Lebbar K [19]. This extension was reflected by an increase in the density of this peri-vesical space [18]. The distant metastases were bone and liver (each 11.76\%). Classically metastases are late in bladder tumors 
[19].

The limits of our study were:

- The high cost of the scanner and the low osmolarity contrast medium.

- Reactions related to the contrast medium generally in the form of vomiting and one case of allergic reaction of post-injection urticaria.

- Lack of histology results in some patients.

- No patient had undergone an MRI or Pet scan.

\section{Conclusion}

Bladder tumours are common in men with a reserved prognosis. Urinary bilharzia remains the predominant risk factor in endemic countries. The role of medical imaging is important in the management of patients, in order to guide the urologist in his or her therapeutic decisions. It is essential for the assessment of extension, treatment and surveillance. The diagnosis of certainty remains histology.

\section{Conflicts of Interest}

The authors declare no conflicts of interest regarding the publication of this paper.

\section{References}

[1] Mazerolles, C. (2005) The Natural History of Bladder Cancer. Progrès en Urologie, $15,1065-1066$.

[2] Irani, J. (2003) Epidemiology of Bladder Cancer. Progrès en Urologie, 13, 1207-1208.

[3] Johansson, S.L. and Cohen, S.M. (1997) Epidemiology and Etiology of Bladder Cancer. Seminars in Surgical Oncology, 13, 291-298. https://doi.org/10.1002/(SICI)1098-2388(199709/10)13:5<291::AID-SSU2>3.0.CO;2 $-8$

[4] Ferlay, J., Bray, F., Parkim, D.M., Pisani, P., et al. (2010) Cancer Incidence and Mortality in Europe in 2008. European Journal of Cancer, 46, 756-810. https://doi.org/10.1016/j.ejca.2009.12.014

[5] Diao, B., Amath, T., Fall, B., et al. (2008) Epidemiology of Bladder Cancer in Senegal. Progrès en Urologie, 18, 445-448. https://doi.org/10.1016/j.purol.2008.04.016

[6] Sangho, H., Keita, A.D., Ouattara, Z., et al. (2009) Urinary Schistosomiasis and Bladder Cancer in a Hospital in Bamako (Mali). Medicine of Black Africa, 56, 515.

[7] Roy, C., Tuchmann, C., Guth, S. and Saussine, C. (2000) Bladder Pathologies: Performance and Limitations of Imaging Methods. Journal of Radiology, 81, 1099-1111.

[8] Roy, C. and Merran, S. (2002) Imaging and Tumour Pathology of the Bladder. Journal of Radiology, 83, 843.

[9] Vikram, R., Sandler, C.M. and Ng, C.S. (2009) Imaging and Staging of Transitional Cell Carcinoma: Part 2, Upper Urinary Tract. American Journal of Roentgenology, 192, 1488-1493. https://doi.org/10.2214/AJR.09.2577

[10] Park, S.B., Kim, J.K., Lee, H.J., Choi, H.J. and Cho, K.S. (2007) Hematuria: Portal Venous Phase Multidetector Row CT of the Bladder-A Prospective Study. Radiology, 245, 798-805. https://doi.org/10.1148/radiol.2452061060 
[11] Roupret, M., Zigeuner, R., Palou, J., Boehle, A., Kaasinen, E., Sylvesterr, et al. (2011) European Guidelines for the Diagnosis and Management of Upper Urinary Tract Urothelial Cell Carcinomas: 2011 Update. European Urology, 59, 584-594. https://doi.org/10.1016/j.eururo.2010.12.042

[12] Diarra, B. (2011) Radiological and Epidemiological Study of Bladder Tumours in the Radiology Department of the Point G Hospital. Thesis, Medicine Bamako Mali.

[13] Peyromaure, M., Weibing, S., Sebe, P., et al. (2002) Prognostic Value of p53 Overexpression in T1G3 Bladder Tumors Treated with Bacillus Calmette-Guerin Therapy. Urology, 59, 409-413. https://doi.org/10.1016/S0090-4295(01)01551-5

[14] Fahmy, N., Kassouf, W., Jeyaganth, S., et al. (2008) An Analysis of Pre Operative Delays Prior to Radical Cystectomy for Bladder Cancer in Quebec. Canadian Urological Association Journal, 2, 102-108.

[15] Elmahfoudi, A. and Sarf, I. (2013) Epidemiological Profile of Bladder Tumors in the Marrakech Region. Thesis N 32/2013 Faculty of Medicine and Pharmacy-Marrakech.

[16] Tangara, S. (2008) Study of Bladder Tumours in the Urology Department of CHU Gabriel Toure about 50 Cases. Medical Thesis, Bamako 2008, 66-73.

[17] Gurou, B., Amath, T., Fall, B., et al. (2008) Epidemiology of Bladder Cancer in Senegal. Progrès en Urologie, 18, 445-448.

[18] Zerbib, M. and Bouchot, O. (2008) Treatment of Infiltrating Bladder Tumours. Report of the 2002 AFU Congress. Progrès en Urologie, 12, 735-1178.

[19] Lebrar, K., Amil, T., Ameur, A., et al. (2001) Place of Imaging in Bladder Tumours. Medicine of the Magrheb, 86, 31-37.

[20] Keïta, A.D., Sacko, M., Toure, M., et al. (2009) Imaging of Urological Tumours in a Bilharzian Endemic area in Mali. African Journal of Cancer, 1, 135-140.

https://doi.org/10.1007/s12558-009-0015-2 
Appendix

INDIVIDUAL SURVEY FORM

$\mathrm{N}^{\circ}$

ID: PATIENT

NAME:

AGE:

GENDER:

OCCUPATION

ANTECEDENTS/RISK FACTORS:

-MEDICAL:

1) Bilharzia

2) Dye

3) Tobacco/smoking

4) Chronic cystitis

5) Absent

-SURGICAL:

-TOXIC:

-FAMILY:

URO-TDM PATTERN:

-Hematuria:

-Irritative syndrome:

-Obstructive syndrome:

-Nephritic colic:

-Adventitious discovery:

OTHER IMAGING:

1) Intravenous Urography

2) Subpubic echography: a) Yes b) No
3) Others:
a) MRI
b) Cystography

\section{URO-CT EXAMINATION:}

Date performed: .1

TECHNICAL: 1) Without IV iodine: $-\mathrm{C} \quad$ 2) with IV iodine: $+\mathrm{C}$ :

Thickness of the sections:

PROTOCOL: -C/ARTERIAL/PORTAL/UROGRAPHY

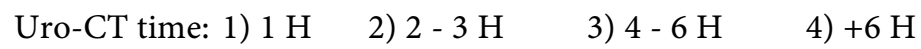

CHARACTERISTICS OF THE LESION

DENSITY
1) Tissue
a) Yes:
b) No:
2) Necrotic
a) Yes:
b) No:
3) Calcifications
a) Yes:
b) No:
Outline
1) Regular

2) Regular

Seat:

-Lateral face:

1) Right:

2) Left:

1) Anterior:

2) Posterior:

3) Col:

4) Trigone: 
5) Bladder dome: 6) Right ureteral orifice: 7) Left ureteral orifice:

8) All bladder:

NUMBER: $\quad$ 1) Single: 2) Multiple:

TYPE: 1) Flat: 2) Protruding: 3) Budding:

$\begin{array}{lll}\text { SIZE: } & \text { 1) Less than or equal to } 3 \mathrm{~cm} & \text { 2) Greater than } 3 \mathrm{~cm}\end{array}$

CONTRAST: 1) Absent: 2) Homogeneous: 3) Heterogeneous:

4) Rough 5) Moderate 6) Intense

Retention on the top of the apparatus:
1) Yes:
2) No:

Extension:

Local:

peri-vesical fat infiltration:
1) Yes:
2) No:

Locoregional:
1) Prostate:
2) Uterus:
3) Ureter:
4) Rectum:
5) Urethra:
6) Sigmoid:

7) Other:

- LYMPH NODE: 1) Yes:
Number:
1) 1
2) 2 - 3
3) More 3
Location:
1) Internal
2) External
3) Lumbo-aortic
4) Peripheral

Size: $\mathrm{mm}$

- REMOTE LESION
1) Bone:
a) Yes:
b) No:
2) Liver:
a) Yes:
b) No:
3) Lung:
a) Yes:
b) No:
4) Pleura
a) Yes:
b) No:
5) Others:
a) Yes:
b) No:

Patient agreement: 1) yes 2) no 